\title{
Photodecarbonylation of dibenzyl ketones and trapping of radical intermediates by copper(II) chloride in frozen aqueous solutions
}

\author{
Radovan Ruzicka, Lenka Baráková, and Petr Klán* \\ Department of Organic Chemistry, Faculty of Science, Masaryk University, Kotlarska 2, CZ - \\ 61137 Brno, Czech Republic \\ in The Journal of Physical Chemistry B
}

Experimental Section - Synthesis of the starting compounds and photoproducts

4-Methyldibenzyl ketone (MeDBK) was synthesized according to a known procedure ${ }^{1}$ and purified by column chromatography (silica gel; ether/hexane, 1:10) to give a $68 \%$ yield. Mp. $21.4-22.9{ }^{\circ} \mathrm{C} ;{ }^{1} \mathrm{H}$ NMR $\left(300 \mathrm{MHz}, \mathrm{CDCl}_{3}\right) \delta(\mathrm{ppm}) 2.44(\mathrm{~s}, 3 \mathrm{H}), 3.76(\mathrm{~s}, 2 \mathrm{H}), 3.78(\mathrm{~s}, 2 \mathrm{H})$, $7.17-7.40(\mathrm{~m}, 9 \mathrm{H}) ;{ }^{13} \mathrm{C}$ NMR $\left(75.5 \mathrm{MHz}, \mathrm{CDCl}_{3}\right) \delta(\mathrm{ppm}) 21.26,48.94,49.18,127.22$, $128.89,129.56,129.63,129.72,131.15,134.33,136.88,206.02$; MS (EI) $m / z 224\left(\mathrm{M}^{+}\right), 105$, $91,77,65,51$.

4,4'-Dimethyldibenzyl ketone (diMeDBK). p-Tolylmethylcarboxylic acid (8 g, $58 \mathrm{mmol})$ was intensively stirred with $\mathrm{CaO}(6.9 \mathrm{~g}, 120 \mathrm{mmol})$ at $140{ }^{\circ} \mathrm{C}$ without solvent for 4 hours. The product was distilled off directly from the reaction mixture and purified by column chromatography (silica gel; ether/hexane, 1:10). Yield $58 \%$; mp. $51.2-52.8{ }^{\circ} \mathrm{C} ;{ }^{1} \mathrm{H}$ NMR $\left(300 \mathrm{MHz}, \mathrm{CDCl}_{3}\right) \delta(\mathrm{ppm}) 2.36(\mathrm{~s}, 6 \mathrm{H}), 3.68(\mathrm{~s}, 4 \mathrm{H}), 7.06(\mathrm{~d}, J=7.93 \mathrm{~Hz}, 4 \mathrm{H}), 7.15(\mathrm{~d}, J=$ $7.60 \mathrm{~Hz}, 4 \mathrm{H}) ;{ }^{13} \mathrm{C}$ NMR $\left(75.5 \mathrm{MHz}, \mathrm{CDCl}_{3}\right) \delta(\mathrm{ppm}) 21.26,48.80,129.57,129.61,131.25$, 136.84, 206.28; MS (EI) $m / z 238\left(\mathrm{M}^{\dagger}\right), 132,105,77$. 
1-Methyl-4-phenethylbenzene (MeDPE). Title compound was prepared from phenylacetic acid $(8.4 \mathrm{~g}, 69 \mathrm{mmol})$, toluene $(30 \mathrm{ml}, 284 \mathrm{mmol})$, and $\mathrm{AlCl}_{3}$, following by reduction with $\mathrm{LiAlH}_{4}$ according to literature. ${ }^{1}$ The crude product was purified on a silica gel column with hexane as a mobile phase. Yield $43 \%$; mp. $26.4-28.1{ }^{\circ} \mathrm{C} ;{ }^{1} \mathrm{H}$ NMR $\left(300 \mathrm{MHz}, \mathrm{CDCl}_{3}\right) \delta$ (ppm) 2.37 (s, 3H), $2.94(\mathrm{~s}, 4 \mathrm{H}), 7.13-7.32(\mathrm{~m}, 9 \mathrm{H}) ;{ }^{13} \mathrm{C} \mathrm{NMR}\left(75.5 \mathrm{MHz}, \mathrm{CDCl}_{3}\right) \delta(\mathrm{ppm})$ 21.22, 37.70, 38.28, 126.08, 128.51, 128.66, 129.22, 135.54, 138.94, 142.13; MS (EI) $m / z 196$ $\left(\mathrm{M}^{+}\right), 105,91,77,65,51$.

1,2-Dimethyl-4-phenethylbenzene (diMeDPE) was prepared by photolysis of 4,4'dimethyldibenzyl ketone $(1 \mathrm{~g}, 4 \mathrm{mmol})$ in cyclohexane in a Pyrex reactor $(\lambda>280 \mathrm{~nm})$ to a quantitative conversion. The solvent was evaporated and the product was purified by column chromatography (silica gel; hexane). Yield $82 \%$; mp. $77.6-79.6{ }^{\circ} \mathrm{C} ;{ }^{1} \mathrm{H}$ NMR $(300 \mathrm{MHz}$, $\left.\mathrm{CDCl}_{3}\right) \delta(\mathrm{ppm}) 2.35(\mathrm{~s}, 6 \mathrm{H}), 2.89(\mathrm{~s}, 4 \mathrm{H}), 7.11(\mathrm{~s}, 8 \mathrm{H}) ;{ }^{13} \mathrm{C} \mathrm{NMR}\left(75.5 \mathrm{MHz}, \mathrm{CDCl}_{3}\right) \delta$ (ppm) 21.22, 37.84, 128.51, 129.22, 135.50, 139.09; MS (EI) $m / z 210\left(\mathrm{M}^{+}\right), 105,77$.

\section{Reference}

(1) Turro, N. J.; Weed, G. C. J. Am. Chem. Soc. 1983, 105, 1861. 